\title{
Comparison of the effects of horizontal and vertical micro-osteoperforations on the biological response and tooth movement in rabbits
}

\author{
Seok-gon Kim ${ }^{\mathrm{a}}$ (1) \\ Yoon-Ah Kook ${ }^{\mathrm{b}}$ (i) \\ Hee Jin Lim $^{\mathrm{b}}$ \\ Patrick Park ${ }^{\mathrm{c}}$ \\ Won Lee ${ }^{\mathrm{d}}$ \\ Jae Hyun Park ${ }^{\mathrm{e}, \mathrm{f}}$ \\ Mohamed Bayome $\mathrm{g}^{\mathrm{g}, \mathrm{h}}$ \\ Yoonji Kim ${ }^{\mathrm{b}}$
}

${ }^{a}$ Department of Orthodontics, Graduate School of Clinical Dental Science, The Catholic University of Korea, Seoul, Korea

${ }^{b}$ Department of Orthodontics, Seoul St. Mary's Hospital, College of Medicine, The Catholic University of Korea, Seoul, Korea

'Santa Monica College, Santa Monica, CA, USA

${ }^{\mathrm{d}}$ Division of Oral and Maxillofacial Surgery, Department of Dentistry, Uijeongbu St. Mary's Hospital,

The Catholic University of Korea, Uijeongbu, Korea

'Postgraduate Orthodontic Program, Arizona School of Dentistry \&t Oral Health, A.T. Still University, Mesa, AZ, USA

International Scholar, Graduate School of Dentistry, Kyung Hee University, Seoul, Korea

${ }^{g}$ Department of Preventive Dental Sciences, College of Dentistry, King Faisal University, Al-Ahsa, Kingdom of Saudi Arabia

hepartment of Postgraduate Studies, Universidad Autonoma del Paraguay, Asuncion, Paraguay 


\section{INTRODUCTION}

With an increase in the demand for orthodontic treatment in adults, long treatment time is often the principal factor that influences patient satisfaction. As acceleration of tooth movement has become the primary concern of clinicians, many studies have been conducted to investigate accelerated tooth movement. ${ }^{1-3}$

Surgical acceleration of tooth movement can be explained by the regional acceleratory phenomenon (RAP), wherein injury to the bone results in temporary demineralization-remineralization of the involved bone areas. Tooth movement is expedited as resistance offered by the dense cortical bone is removed. ${ }^{4,5}$

Among the available modalities, corticotomy is the most effective, because it induces the RAP and stimulates tooth movement on the buccal side. ${ }^{6,7}$ Less invasive techniques such as piezocision, corticision, and microosteoperforation (MOP) without flap elevation have also been reported to be effective. ${ }^{8-13}$

Wilcko et al. ${ }^{14}$ applied selective decortication lines and made cuts as deep as $0.5 \mathrm{~mm}$ around the target teeth, and Baloul et al. ${ }^{15}$ demonstrated that this surgical intervention accelerated the rate of tooth movement during the early stages of treatment. Dutra et al. ${ }^{16}$ reported that alveolar decortications resulted in enhanced bone remodeling in the region of tooth movement. In addition, some studies have demonstrated that MOP significantly shortens the duration of orthodontic treatment. ${ }^{8,17}$ Recently, two randomized controlled studies assessed the effect of MOP on tooth movement. ${ }^{18,19}$ Sivarajan et al. ${ }^{18}$ found a statistical increase in tooth movement but not a clinically significant one. Meanwhile, Aboalnaga et al. ${ }^{19}$ reported no significant effect of MOP on canine retraction. Moreover, a systematic review by $\mathrm{Fu}$ et al. ${ }^{20}$ revealed no evidence that a single application of MOP accelerated tooth movement.

In contrast, vertical osteotomy of the alveolar extraction socket accelerated canine distalization into the first premolar (P1) extraction space. Liou and Huang ${ }^{21}$ created vertical grooves inside the extraction socket and discovered that the canines showed $6.5 \mathrm{~mm}$ of distal movement in three weeks without any significant complications. Yu et al. ${ }^{22}$ evaluated the histologic effects and the rate of orthodontic tooth movement after vertical osteoperforation in the mandibles of rabbits and found that it resulted in greater tooth movement. In addition, McBride et al. ${ }^{23}$ undermined the interseptal bone by creating vertical grooves in dogs and concluded that less dense and less mature bone was induced by these surgical insults. However, no study has compared the histologic effects obtained through vertical osteotomy and MOP or compared the resultant amount of tooth movement.
Therefore, the aim of this study was to compare the rate of tooth movement after multiple horizontal (MH) and single vertical (SV) MOPs, and to evaluate the histological changes in response to orthodontic force application following the surgical procedure in rabbits. The null hypothesis was that there will be no significant differences between MH and SV MOPs in terms of their biologic effect and resultant tooth movement.

\section{MATERIALS AND METHODS}

The study sample comprised the mandibular halves of 24 male New Zealand white rabbits (mean age, 14 weeks) weighing 1.7 to $3.1 \mathrm{~kg}$. For one week before the experiments, the animals were acclimatized in individual cages under a controlled temperature $\left(22.0 \pm 2.0^{\circ} \mathrm{C}\right)$ and 12 -h light/dark periods; they had free access to water and a commercial diet. The Institutional Animal Care and Use Committee of Uijeongbu St. Mary's Hospital, The Catholic University of Korea (approval number: UJA2018-04) approved the animal experimental protocol employed in this study.

\section{Experimental and orthodontic procedures}

All rabbits underwent two experimental procedures: SV MOP on the right side of the mandible and MH MOP on the left side of the mandible. The surgical procedures were performed by a single operator in a region $1 \mathrm{~mm}$ mesial to the mandibular P1 under general anesthesia administrated intramuscularly $(35.0-\mathrm{mg} / \mathrm{kg}$ ketamine and $5.0-\mathrm{mg} / \mathrm{kg}$ Xylazine). This region was selected because it is an edentulous region that resembles the atrophied alveolar ridge in humans.

At the MH MOP sites, six horizontal MOPs (1.0-mm wide and $1.5-\mathrm{mm}$ deep) were performed using a straight fissure bur (MCTB10, Yongin, Korea) $1.0 \mathrm{~mm}$ in diameter revolving at $600 \mathrm{rpm}$ with copious saline irrigation. Three MOPs were performed on the buccal side and three on the lingual. At the SV MOP sites, only one vertical MOP (1.4 mm in width and $4.6 \mathrm{~mm}$ in depth) was performed at the crest of the ridge by using a fissure bur (MCTBIO) $1.4 \mathrm{~mm}$ in diameter revolving at $600 \mathrm{rpm}$ with copious saline irrigation. The depths of the MOPs were controlled via markers on the burs. The bone defect volume was intended to be similar in the $\mathrm{MH}$ and SV MOP groups. Nickel-titanium closed-coil springs (Ultimate Wireforms Inc., Bristol, CT, USA) were connected between the P1s and the anterior teeth to deliver 100 $\mathrm{cN}$ of traction force, as shown in Figure 1.

The rabbits were divided randomly into three groups according to sacrifice time, i.e., 1, 2, and 3 weeks after the experimental procedure. At each time point, eight rabbits were sacrificed with an overdose of potassium chloride under a double dose of ketamine. 
A

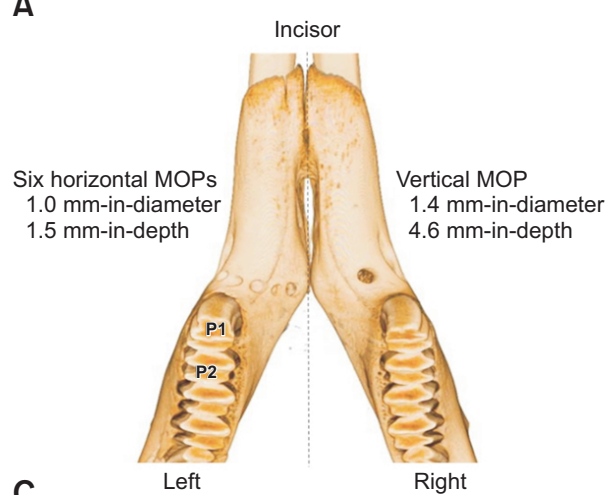

C

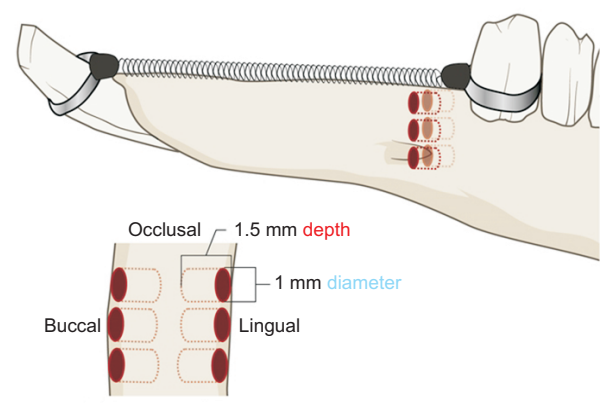

Multiple horizontal (MH) osteoperforation
B
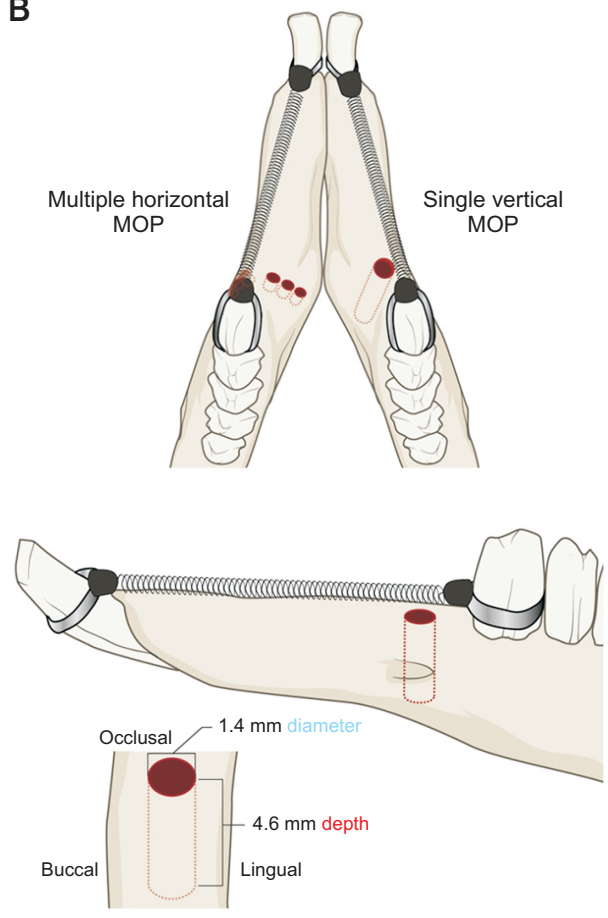

Single vertical (SV) osteoperforation
Figure 1. A, Three-dimensional micro-computed tomography reconstructed scan of the left-sided multiple horizontal $(\mathrm{MH})$ microosteoperforations (MOPs) and the right-sided single vertical (SV) MOP. B, A force of 100 $\mathrm{CN}$ is applied by connecting the anterior teeth to the first premolars by using nickeltitanium closed-coil springs. C, Design of the six MH MOPs and the SV MOP.

P1, first premolar; P2, second premolar.

\section{Micro-computed tomography imaging}

After sacrificing the animals, micro-computed tomography (CT) images of the 24 mandibles were acquired at $130 \mathrm{kV}$ and $60 \mu \mathrm{A}$ using a lab scanner (SkyScan 1173; Bruker-CT, Kontich, Belgium) for morphometric analysis. The images were reconstructed using the scanner software. The bone volume and percentage bone volume were calculated using CT-Analyser 1.14.4.1 (Bruker-CT). The region of interest extended for $3 \mathrm{~mm}$ mesially, starting from the mesial surface of the P1 root. Vertically, it extended coronal to the plane passing through the $\mathrm{P} 1$ root apex parallel to the occlusal plane.

\section{Tooth movement}

On the micro-CT images, tooth movement was measured by a single investigator from the center of the distal marginal ridge of the $\mathrm{P} 1$ to the center of the mesial marginal ridge of the second premolar (P2) (Figure 2). The distance between these two points before traction was assumed to be zero as in an intact contact point between the two premolars. Several weeks later, the sample was remeasured to assess intraobserver reliability. Intraclass correlation coefficients were calculated, and the values ranged between 0.997 and 1.00 .

\section{Tissue preparation}

The specimens extended from the P2 to $8 \mathrm{~mm}$ mesial to the P1 and were fixed for 24 hours in $4 \%$ paraformaldehyde at $4^{\circ} \mathrm{C}$, decalcified in $10 \%$ ethylenediamine-

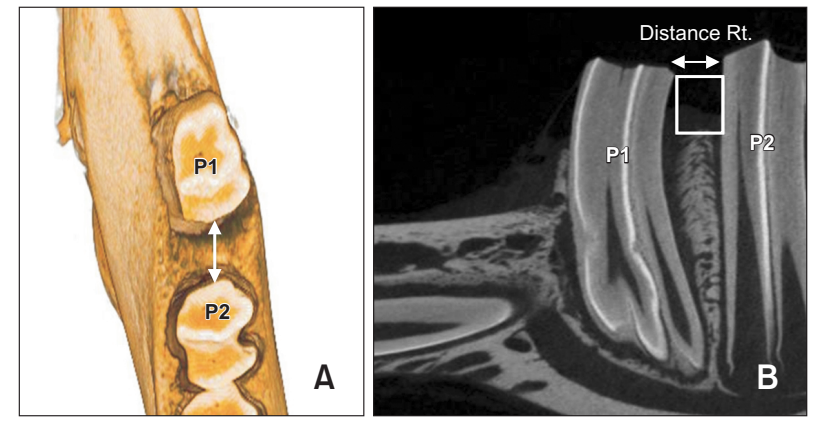

Figure 2. Tooth movement distance. $A_{1}$ Occlusal section. B, Sagittal section; white arrow, the amount of tooth movement.

P1, first premolar; P2, second premolar; Rt, right.

tetraacetic acid using BioWave Pro (PELCO, Fresno, CA, USA), embedded in paraffin, sectioned into $4-\mu \mathrm{m}$-thick mesiodistal slices, and stained with hematoxylin and eosin. The regions of interest were mesial to the $\mathrm{P} 1$ and between the P1and P2.

\section{Tartrate-resistant acidic phosphatase-positive cell count}

To confirm the presence of osteoclasts, tartrateresistant acidic phosphatase (TRAP) staining was applied following a previously described protocol. ${ }^{24}$ Digital slide images of the region $8 \mathrm{~mm}$ mesial to the P1 were acquired using PANNORAMIC 250 Flash 111 (3DHISTECH, 
Budapest, Hungary). TRAP-positive cells were counted using CaseViewer 2.0 (3DHISTECH).

\section{Statistical analysis}

Statistical analysis was conducted using IBM SPSS Statistics for Windows, version 20.0 (IBM Corp., Armonk, NY, USA). The Shapiro-Wilk test was applied to confirm normal distribution. Differences in tooth movement, TRAP-positive cell count, and bone variables between the two groups and between the three time points were evaluated using repeated-measures analysis of variance. Significance was set at 0.05 .

\section{RESULTS}

\section{Amount of tooth movement}

The amount of tooth movement showed a significant difference according to the time points $(p=0.001)$. The $\mathrm{MH}$ group showed tooth movements of $0.57 \pm 0.20 \mathrm{~mm}$ at Week 1, $0.89 \pm 0.46 \mathrm{~mm}$ at Week 2, and $1.47 \pm 0.56$ $\mathrm{mm}$ at Week 3. The SV group showed tooth movements of $0.57 \pm 0.29 \mathrm{~mm}$ at Week $1,0.98 \pm 0.46 \mathrm{~mm}$ at Week 2 , and $1.84 \pm 1.15 \mathrm{~mm}$ at Week 3 . No significant dif- ference was observed between the MH and SV groups. Moreover, no significant difference was observed in tooth movement between Weeks 1 and 2 ( $p=0.322$ ), but a significant difference was observed between Weeks

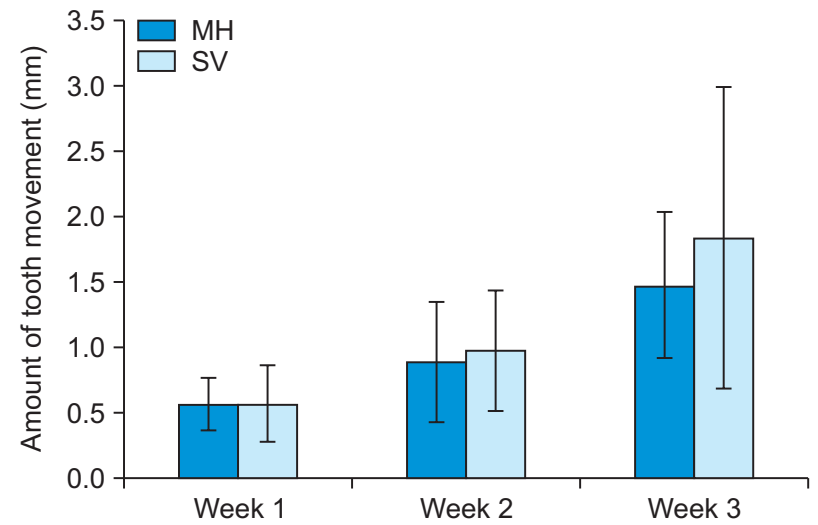

Figure 3. Amount of tooth movement at 1,2, and 3 weeks (mm).

$\mathrm{MH}$, multiple horizontal micro-osteoperforations; SV, single vertical micro-osteoperforation.

Table 1. Amount of tooth movement at week 1, 2, and $3(\mathrm{~mm})$

\begin{tabular}{|c|c|c|c|c|c|c|c|}
\hline \multirow{2}{*}{ Group } & \multirow{2}{*}{$\begin{array}{l}\text { Week } 1 \\
(n=8)\end{array}$} & \multirow{2}{*}{$\begin{array}{l}\text { Week } 2 \\
(n=8)\end{array}$} & \multirow{2}{*}{$\begin{array}{l}\text { Week } 3 \\
(n=8)\end{array}$} & \multirow{2}{*}{$\begin{array}{l}\text { p-value: } \\
\text { timepoint }\end{array}$} & \multicolumn{3}{|c|}{$\begin{array}{l}\text { Multiple comparisons } \\
p \text {-value }\end{array}$} \\
\hline & & & & & w1 vs. w2 & w2 vs. w3 & w1 vs. w3 \\
\hline Multiple horizontal & $0.57 \pm 0.20$ & $0.89 \pm 0.46$ & $1.47 \pm 0.56$ & \multirow{2}{*}{0.001} & \multirow{2}{*}{0.322} & \multirow{2}{*}{0.025} & \multirow{2}{*}{$<0.001$} \\
\hline Single vertical & $0.57 \pm 0.29$ & $0.98 \pm 0.46$ & $1.84 \pm 1.15$ & & & & \\
\hline$p$-value: group & & 0.166 & & & & & \\
\hline
\end{tabular}

Values are presented as mean \pm standard deviation.

Repeated-measure ANOVA: group as within-subjects factor, and timepoint as between-subjects factor.

Multiple comparisons test: Bonferroni post hoc.

Interaction between the timepoint and group: $p=0.297$.

w, week.
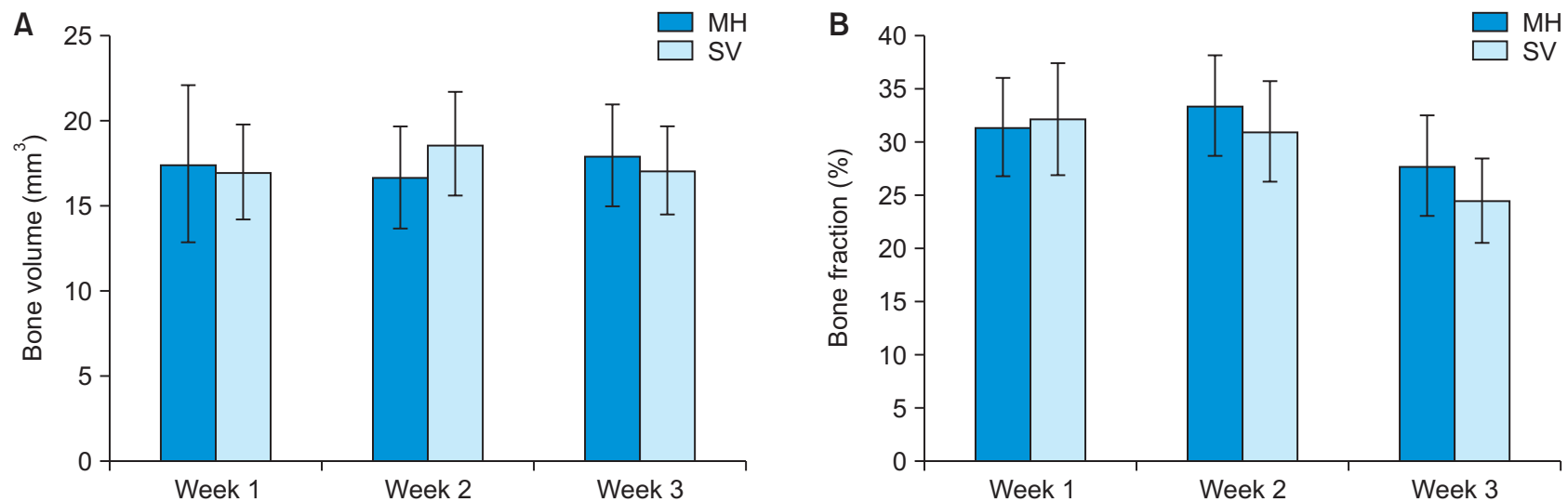

Figure 4. Micro-computed tomography evaluation. A, Bone volume. B, Bone fraction. $\mathrm{MH}$, multiple horizontal micro-osteoperforations; SV, single vertical micro-osteoperforation. 


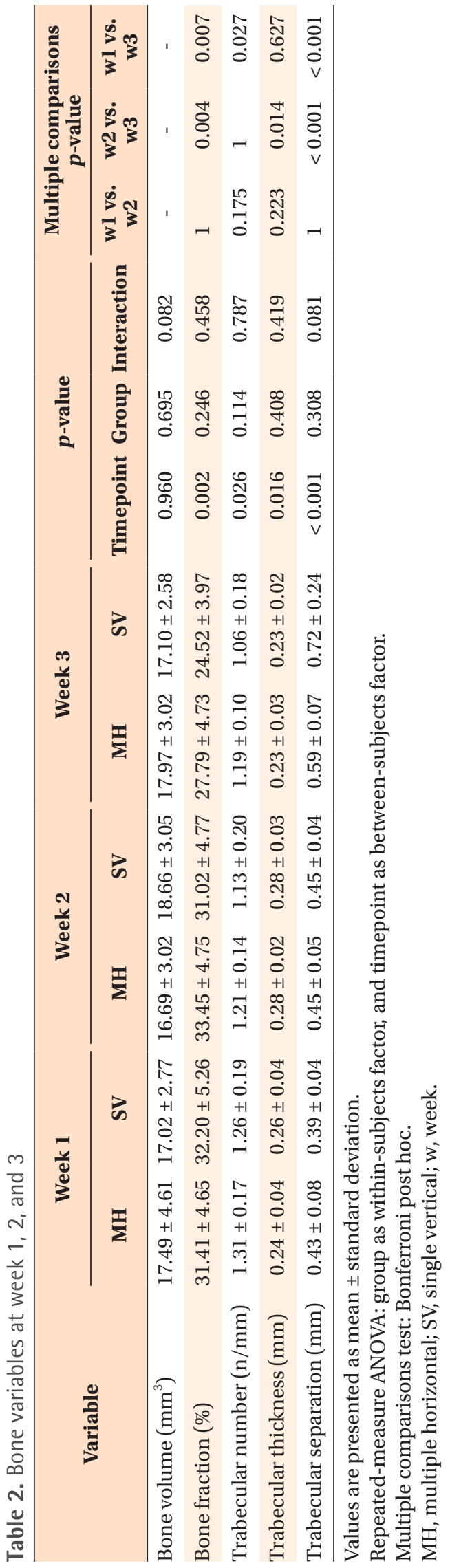

2 and $3(p=0.025)$ and between Weeks 1 and $3(p<$ 0.001), as shown in Figure 3 and Table 1.

\section{Micro-computed tomography bone evaluation}

The bone variables and bone volume showed no significant differences in either group according to the time points. However, the bone fraction was significantly smaller at Week 3 than at Weeks 1 and $2(p=0.007$ and 0.004 , respectively) (Figure 4). Meanwhile, trabecular separation was significantly greater at Week 3 than at Weeks 1 and $2(p<0.001)$. The trabecular number was greater at Week 1 than that at Week $3(p=0.027)$, whereas trabecular thickness was significantly different between Weeks 2 and $3(p=0.014)$, as shown in Table 2 .

\section{Tartrate-resistant acidic phosphatase-positive cell} count

The TRAP-positive cell count showed no significant difference between the MH and SV groups. However, the TRAP-positive cell count was significantly increased between Weeks 1 and 3 ( $p=0.002)$, as shown in Figures 5 and 6 and Table 3.

\section{Microscopic examination of undecalcified specimens}

Microscopic examination of undecalcified specimens revealed a widened periodontal ligament space and an increased number of osteoclast-like cells, especially at Week 3. Moreover, no significant root resorption was noticed in either group (Figure 7).

\section{DISCUSSION}

Alveolar corticotomy-assisted rapid tooth movement is a relatively new technique for adult orthodontic treat-

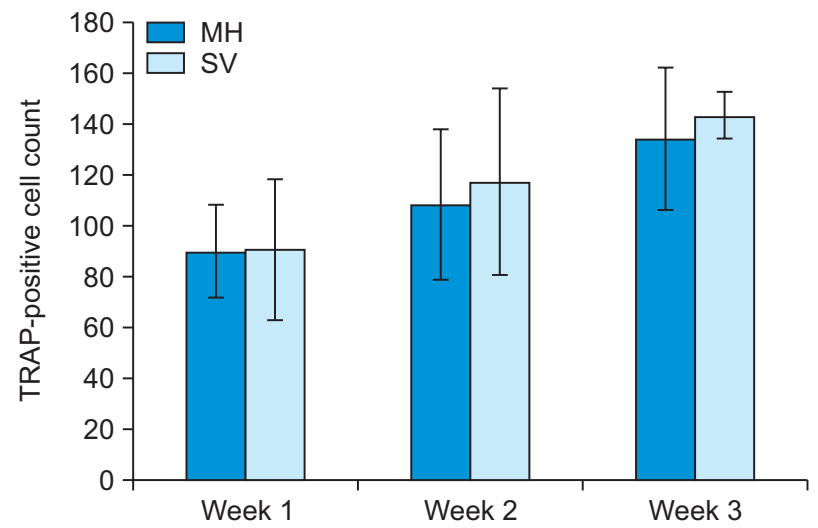

Figure 5. Tartrate-resistant acidic phosphatase (TRAP)positive cell count comparison between the groups and time points.

$\mathrm{MH}$, multiple horizontal micro-osteoperforations; SV, single vertical micro-osteoperforation. 


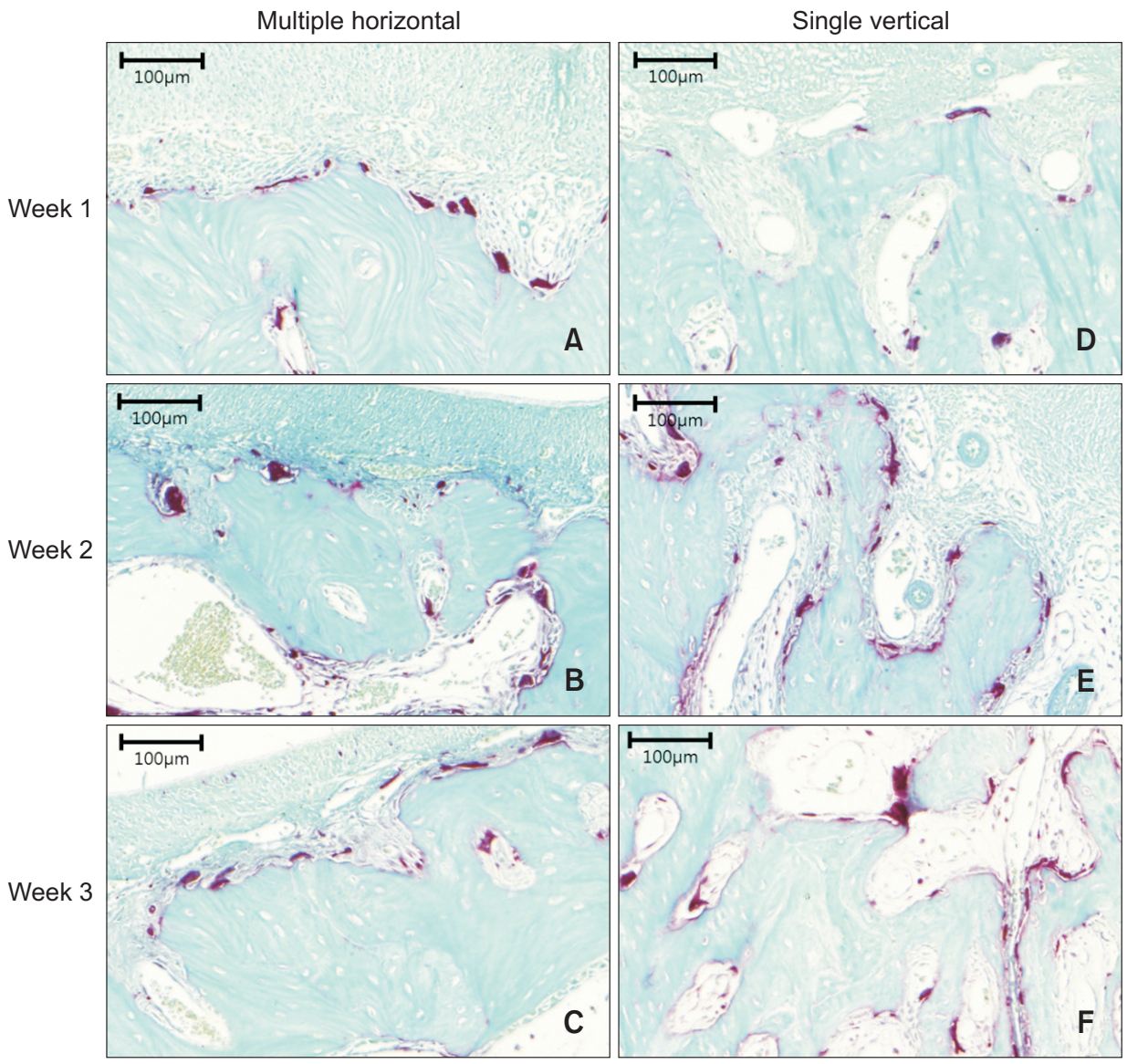

Figure 6. Microphotograph of the periodontal tissues stained with tartrate-resistant acidic phosphatase (TRAP) at $\times 200$ magnification. AC, Multiple horizontal microosteoperforations at Weeks 1,2 , and 3 , respectively. $\mathbf{D}-\mathbf{F}$, Single vertical micro-osteoperforation at Weeks 1, 2, and 3 , respectively. TRAPpositive cells are detectable along the resorbed alveolar bone on the compression side.

Table 3. Tartrate-resistant acidic phosphatase-positive cell count at week 1, 2, and 3

\begin{tabular}{|c|c|c|c|c|c|c|c|}
\hline \multirow{2}{*}{ Group } & \multirow{2}{*}{$\begin{array}{l}\text { Week } 1 \\
(\mathrm{n}=\mathbf{8})\end{array}$} & \multirow{2}{*}{$\begin{array}{l}\text { Week } 2 \\
(\mathrm{n}=8)\end{array}$} & \multirow{2}{*}{$\begin{array}{l}\text { Week } 3 \\
(\mathrm{n}=\mathbf{8})\end{array}$} & \multirow{2}{*}{$\begin{array}{c}p \text {-value: } \\
\text { timepoint }\end{array}$} & \multicolumn{3}{|c|}{$\begin{array}{c}\text { Multiple comparisons } \\
p \text {-value }\end{array}$} \\
\hline & & & & & w1 vs. w2 & w2 vs. w3 & w1 vs. w3 \\
\hline Multiple horizontal & $90.02 \pm 18.28$ & $108.51 \pm 29.64$ & $134.50 \pm 27.79$ & \multirow{3}{*}{0.002} & \multirow{3}{*}{0.214} & \multirow{3}{*}{0.117} & \multirow{3}{*}{0.002} \\
\hline Single vertical & $90.88 \pm 27.63$ & $117.38 \pm 36.87$ & $143.49 \pm 9.21$ & & & & \\
\hline$p$-value: group & & 0.207 & & & & & \\
\hline
\end{tabular}

Values are presented as mean \pm standard deviation.

Repeated-measure ANOVA: group as within-subjects factor, and timepoint as between-subjects factor.

Multiple comparisons test: Bonferroni post hoc.

Interaction between the timepoint and group: $p=0.734$.

$\mathrm{w}$, week.

ment. Nevertheless, several recent studies have examined the utility of MOP, which does not require flap elevation. ${ }^{21-23}$

In a previous study, Kim et al. ${ }^{25}$ reported no significant differences in both the amount of tooth movement and the number of TRAP-positive osteoclasts between the corticotomy and flapless MOP groups. Therefore, in our study, we adjusted the vertical and horizontal MOPs to expand the region of the RAP. A single large injury was created vertically, and multiple small injuries were cre- ated horizontally, but the amount of bone removed in both the methods was intended to be the same.

MOP was performed in a region $1 \mathrm{~mm}$ mesial to the P1. Cramer et al. ${ }^{26}$ reported that this intervention, which was $3 \mathrm{~mm}$ away from the teeth to be moved, was ineffective in accelerating tooth movement. Moreover, it produced no apparent differences in the mineralization of bones, osteoblasts, and osteoclasts. In addition, van Gemert et al. ${ }^{27}$ demonstrated that the principal effects of MOP were limited to a distance of $1.5 \mathrm{~mm}$. 


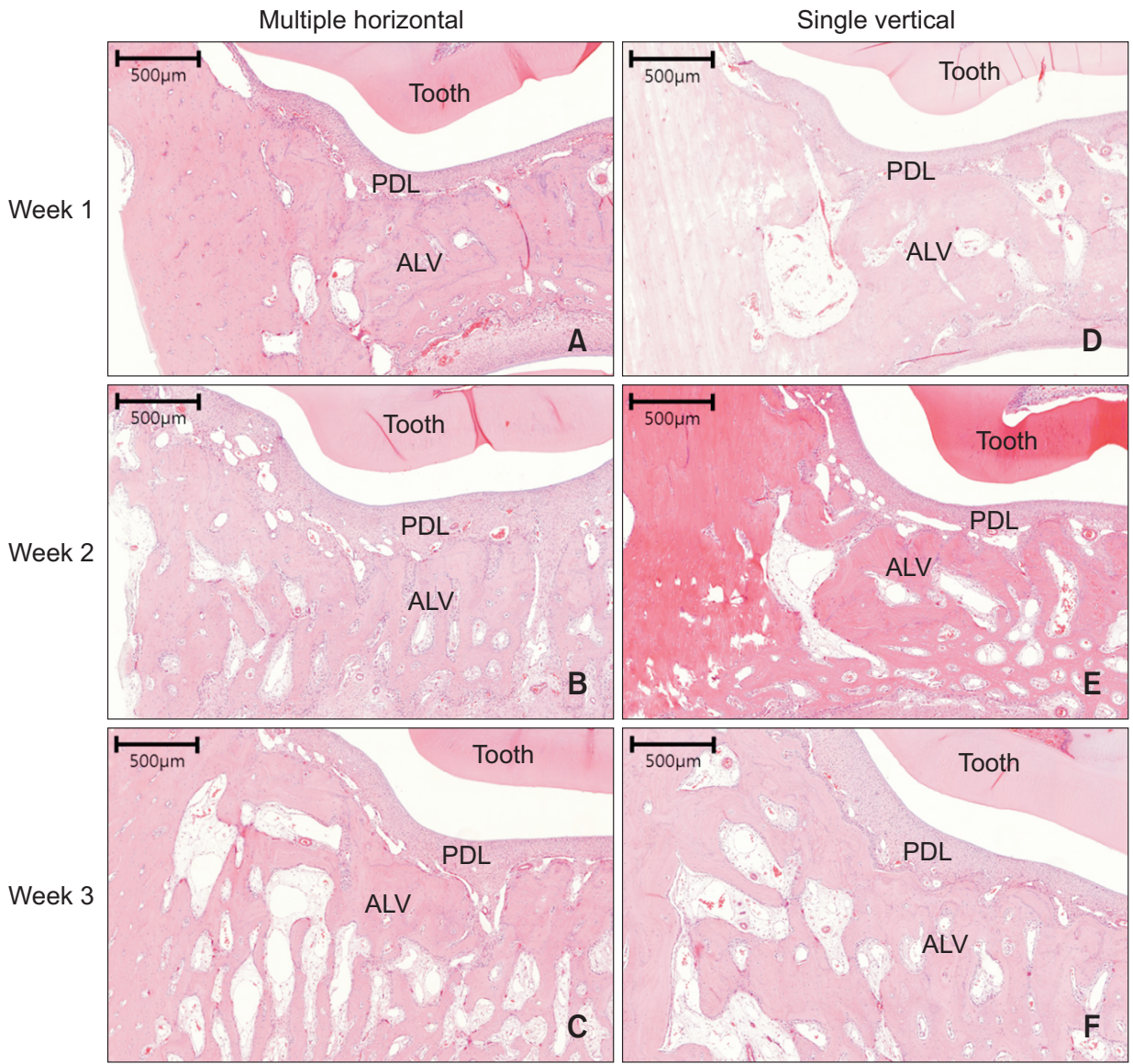

Figure 7. Microphotograph of a buccolingual section at the mesial periodontium of the first premolar stained with hematoxylin and eosin at $\times 40$ magnification. A-C, Multiple horizontal microosteoperforations at Weeks 1, 2, and 3, respectively. DF, Single vertical microosteoperforation at Weeks 1 , 2 , and 3, respectively. Note the widened periodontal ligament (PDL) space in $\mathrm{C}$ and $\mathrm{F}$. ALV, alveolar bone.
In our study on rabbits, tooth movement increased over time, but without a significant difference between the $\mathrm{MH}$ and SV groups $(1.5 \mathrm{~mm}$ and $1.8 \mathrm{~mm}$, respectively at Week 3). Previous studies showed $2.3 \mathrm{~mm}$ of tooth movement at the fourth week after a horizontal MOP ${ }^{25}$ and $1.6 \mathrm{~mm}$ at the third week after a vertical MOP. ${ }^{22}$ Chen et al. ${ }^{28}$ conducted a study on rabbits and reported $0.9 \mathrm{~mm}$ of tooth movement two weeks after corticotomy in the experimental group but just $0.8 \mathrm{~mm}$ of movement in the control group. In our study, both groups showed $0.9 \mathrm{~mm}$ of tooth movement at Week 2 .

Liou and Huang ${ }^{21}$ created vertical grooves inside extraction sockets for rapid tooth movement. They showed that the canines were distracted $6.5 \mathrm{~mm}$ without significant distal tipping or other complications during three weeks. However, another study claimed three MOPs were ineffective for canine retraction. ${ }^{29}$

In our study, micro-CT analysis revealed no significant difference in bone volume and bone fraction between the $\mathrm{MH}$ and SV groups, but bone fraction showed a significant decrease at Week 3. McBride et al. ${ }^{23}$ found that the density of bone material was lower in extraction sockets wherein vertical grooves were created than in those wherein none were created. Nevertheless, no dif- ference was observed in bone volume.

Our study also revealed no significant differences in trabecular number, thickness, and separation between the MH and SV groups. The trabecular number decreased, and trabecular separation increased at Week 3. In contrast, McBride et al. ${ }^{23}$ performed histologic evaluations that showed increased numbers of osteoclasts and greater bone surface areas on the side of the insult. This might be due to differences in the number and volume of MOPs as well as the absence of flap elevation in our study.

Regarding root resorption, Tsai et al. ${ }^{9}$ demonstrated that the MOP group showed lower root resorption than did the control group. However, Murphy et al. ${ }^{30}$ found no significant effect of corticision on root resorption. Patterson et al. ${ }^{31}$ demonstrated that piezocision applied to initiate the RAP may increase root resorption when used in conjunction with orthodontic forces. Nevertheless, our study showed no significant root resorption in either the horizontal or vertical MOP group. The disagreement among the results of these studies might be due to the different study protocols and the different methods used for recording root resorption. Further investigations on the effect of the surgically induced RAP 
on root resorption are warranted.

Kim et al. ${ }^{25}$ reported no significant difference in TRAP-positive cell counts between the two corticotomy groups and a horizontal MOP group. However, Yu et al. ${ }^{22}$ reported an increased number of TRAP-positive cells after vertical osteoperforation. Chen et al. ${ }^{28}$ also reported gradual increases in the osteoclast count at Weeks 1 and 2 after decortication in the experimental group than in the control group. Likewise, Zou et al. ${ }^{32}$ found a greater number of osteoclasts and stronger staining for the osteogenic marker at Weeks 1, 2, and 4 in the corticotomy group than in the control group. In our study, a significant increase was observed in the TRAP-positive cell count between Weeks 1 and 3. However, no significant difference was observed in the number of osteoclasts between the MH and SV groups. This similarity in the histologic findings might explain the absence of differences in the amount of tooth movement between the two groups.

The lack of a control group for comparison might be considered a drawback of this study; therefore, future studies including a control group in a split-mouth design are recommended. Moreover, it might have been better if the $\mathrm{MH}$ and SV procedures were randomized between the right and left sides. Further randomized controlled studies on different osteoperforation techniques, such as $\mathrm{MH}$ and SV MOPs, might also help evaluate the effects of these treatment modalities. Furthermore, future studies might focus on the pain and discomfort experienced by patients undergoing vertical and horizontal MOPs.

\section{CONCLUSION}

Both the MH and SV MOP techniques were able to generate a RAP, since the TRAP-positive osteoclast count was significantly greater at Week 3 than at Week 1 in both the groups.

The effectiveness of the RAP generated by both techniques was similar since the amount of tooth movement, bone variables, and TRAP-positive cell counts showed no significant differences between the two groups over the three time points.

This suggests that an SV MOP might be an effective tool for enhancing tooth movement, especially with molar distalization, uprighting, and protraction in an edentulous area.

\section{CONFLICTS OF INTEREST}

No potential conflict of interest relevant to this article was reported.

\section{REFERENCES}

1. Igarashi K, Mitani H, Adachi H, Shinoda H. Anchorage and retentive effects of a bisphosphonate (AH$\mathrm{BuBP}$ ) on tooth movements in rats. Am J Orthod Dentofacial Orthop 1994;106:279-89.

2. Işeri H, Kişnişci R, Bzizi N, Tüz H. Rapid canine retraction and orthodontic treatment with dentoalveolar distraction osteogenesis. Am J Orthod Dentofacial Orthop 2005;127:533-41; quiz 625.

3. Patterson BM, Dalci 0, Darendeliler MA, Papadopoulou AK. Corticotomies and orthodontic tooth movement: a systematic review. J Oral Maxillofac Surg 2016;74:453-73.

4. Gantes B, Rathbun E, Anholm M. Effects on the periodontium following corticotomy-facilitated orthodontics. Case reports. J Periodontol 1990;61:234-8.

5. Chung KR, Oh MY, Ko SJ. Corticotomy-assisted orthodontics. J Clin Orthod 2001;35:331-9.

6. Kook YA, Lee W, Kim SH, Chung KR. Corticotomyassisted space closure in adult patients with missing lower molars. J Clin Orthod 2013;47:85-95; quiz 139.

7. Mostafa YA, Mohamed Salah Fayed M, Mehanni S, ElBokle NN, Heider AM. Comparison of corticotomyfacilitated vs standard tooth-movement techniques in dogs with miniscrews as anchor units. Am J Orthod Dentofacial Orthop 2009;136:570-7.

8. Ruso S, Campbell PM, Rossmann J, Opperman LA, Taylor RW, Buschang PH. Bone response to buccal tooth movements-with and without flapless alveolar decortication. Eur J Orthod 2014;36:613-23.

9. Tsai CY, Yang TK, Hsieh HY, Yang LY. Comparison of the effects of micro-osteoperforation and corticision on the rate of orthodontic tooth movement in rats. Angle Orthod 2016;86:558-64.

10. Librizzi Z, Kalajzic Z, Camacho D, Yadav S, Nanda R, Uribe F. Comparison of the effects of three surgical techniques on the rate of orthodontic tooth movement in a rat model. Angle Orthod 2017;87:717-24.

11. Hatrom AA, Zawawi KH, Al-Ali RM, Sabban HM, Zahid TM, Al-Turki GA, et al. Effect of piezocision corticotomy on en-masse retraction. Angle Orthod 2020;90:648-54.

12. Shahabee M, Shafaee H, Abtahi M, Rangrazi A, Bardideh E. Effect of micro-osteoperforation on the rate of orthodontic tooth movement-a systematic review and a meta-analysis. Eur J Orthod 2020;42:211-21.

13. Mittal R, Attri S, Batra P, Sonar S, Sharma K, Raghavan S. Comparison of orthodontic space closure using micro-osteoperforation and passive self-ligating appliances or conventional fixed appliances. Angle Orthod 2020;90:634-9. 
14. Wilcko MT, Wilcko WM, Pulver JJ, Bissada NF, Bouquot JE. Accelerated osteogenic orthodontics technique: a 1-stage surgically facilitated rapid orthodontic technique with alveolar augmentation. J Oral Maxillofac Surg 2009;67:2149-59.

15. Baloul SS, Gerstenfeld LC, Morgan EF, Carvalho RS, Van Dyke TE, Kantarci A. Mechanism of action and morphologic changes in the alveolar bone in response to selective alveolar decortication-facilitated tooth movement. Am J Orthod Dentofacial Orthop 2011;139(4 Suppl):S83-101.

16. Dutra EH, Ahmida A, Lima A, Schneider S, Nanda R, Yadav S. The effects of alveolar decortications on orthodontic tooth movement and bone remodelling in rats. Eur J Orthod 2018;40:423-9.

17. Charavet C, Lecloux G, Bruwier A, Rompen E, Maes $\mathrm{N}$, Limme $\mathrm{M}$, et al. Localized piezoelectric alveolar decortication for orthodontic treatment in adults: a randomized controlled trial. J Dent Res 2016;95:1003-9.

18. Sivarajan S, Doss JG, Papageorgiou SN, Cobourne MT, Wey MC. Mini-implant supported canine retraction with micro-osteoperforation: a split-mouth randomized clinical trial. Angle Orthod 2019;89:183-9.

19. Aboalnaga AA, Salah Fayed MM, El-Ashmawi NA, Soliman SA. Effect of micro-osteoperforation on the rate of canine retraction: a split-mouth randomized controlled trial. Prog Orthod 2019;20:21.

20. Fu T, Liu S, Zhao H, Cao M, Zhang R. Effectiveness and safety of minimally invasive orthodontic tooth movement acceleration: a systematic review and meta-analysis. J Dent Res 2019;98:1469-79.

21. Liou EJ, Huang CS. Rapid canine retraction through distraction of the periodontal ligament. Am J Orthod Dentofacial Orthop 1998;114:372-82.

22. Yu JY, Lee W, Park JH, Bayome M, Kim Y, Kook YA. Histologic effects of intentional-socket-assisted orthodontic movement in rabbits. Korean J Orthod 2012;42:207-17.

23. McBride MD, Campbell PM, Opperman LA, Dechow $\mathrm{PC}$, Buschang PH. How does the amount of surgical insult affect bone around moving teeth? Am J Orthod Dentofacial Orthop 2014;145(4 Suppl):S92-9.

24. Kim T, Handa A, lida J, Yoshida S. RANKL expression in rat periodontal ligament subjected to a continuous orthodontic force. Arch Oral Biol 2007;52:24450.

25. Kim J, Kook YA, Bayome M, Park JH, Lee W, Choi H, et al. Comparison of tooth movement and biological response in corticotomy and micro-osteoperforation in rabbits. Korean J Orthod 2019;49:205-13.

26. Cramer CL, Campbell PM, Opperman LA, Tadlock $\mathrm{LP}$, Buschang PH. Effects of micro-osteoperforations on tooth movement and bone in the beagle maxilla. Am J Orthod Dentofacial Orthop 2019;155:681-92.

27. van Gemert LN, Campbell PM, Opperman LA, Buschang $\mathrm{PH}$. Localizing the osseous boundaries of micro-osteoperforations. Am J Orthod Dentofacial Orthop 2019;155:779-90.

28. Chen YW, Wang HC, Gao LH, Liu C, Jiang YX, Qu $\mathrm{H}$, et al. Osteoclastogenesis in local alveolar bone in early decortication-facilitated orthodontic tooth movement. PLoS One 2016;11:e0153937.

29. Alkebsi A, Al-Maaitah E, Al-Shorman H, Abu Alhaija E. Three-dimensional assessment of the effect of micro-osteoperforations on the rate of tooth movement during canine retraction in adults with Class 11 malocclusion: a randomized controlled clinical trial. Am J Orthod Dentofacial Orthop 2018;153:771-85.

30. Murphy C, Kalajzic Z, Chandhoke T, Utreja A, Nanda $\mathrm{R}$, Uribe $\mathrm{F}$. The effect of corticision on root resorption with heavy and light forces. Angle Orthod 2016;86:17-23.

31. Patterson BM, Dalci O, Papadopoulou AK, Madukuri $\mathrm{S}$, Mahon J, Petocz P, et al. Effect of piezocision on root resorption associated with orthodontic force: a microcomputed tomography study. Am J Orthod Dentofacial Orthop 2017;151:53-62.

32. Zou M, Li C, Zheng Z. Remote corticotomy accelerates orthodontic tooth movement in a rat model. Biomed Res lnt 2019;2019:4934128. 